\title{
Enhanced Osteogenic and Vasculogenic Differentiation Potential of Human Adipose Stem Cells on Biphasic Calcium Phosphate Scaffolds in Fibrin Gels
}

\author{
Fransisca A. S. van Esterik, ${ }^{1,2}$ Behrouz Zandieh-Doulabi, ${ }^{1}$ \\ Cornelis J. Kleverlaan, ${ }^{2}$ and Jenneke Klein-Nulend ${ }^{1}$ \\ ${ }^{1}$ Department of Oral Cell Biology, Academic Centre for Dentistry Amsterdam (ACTA), University of Amsterdam and \\ Vrije Universiteit Amsterdam, MOVE Research Institute Amsterdam, Amsterdam, Netherlands \\ ${ }^{2}$ Department of Dental Materials Science, Academic Centre for Dentistry Amsterdam (ACTA), University of Amsterdam and \\ Vrije Universiteit Amsterdam, MOVE Research Institute Amsterdam, Amsterdam, Netherlands
}

Correspondence should be addressed to Jenneke Klein-Nulend; j.kleinnulend@acta.nl

Received 1 March 2016; Revised 6 June 2016; Accepted 27 June 2016

Academic Editor: Susan Liao

Copyright (C) 2016 Fransisca A. S. van Esterik et al. This is an open access article distributed under the Creative Commons Attribution License, which permits unrestricted use, distribution, and reproduction in any medium, provided the original work is properly cited.

For bone tissue engineering synthetic biphasic calcium phosphate (BCP) with a hydroxyapatite/ $\beta$-tricalcium phosphate (HA/ $\beta$ TCP) ratio of 60/40 (BCP60/40) is successfully clinically applied, but the high percentage of HA may hamper efficient scaffold remodelling. Whether BCP with a lower HA/ $\beta$-TCP ratio $(\mathrm{BCP} 20 / 80)$ is more desirable is still unclear. Vascular development is needed before osteogenesis can occur. We aimed to test the osteogenic and/or vasculogenic differentiation potential as well as degradation of composites consisting of human adipose stem cells (ASCs) seeded on BCP60/40 or BCP20/80 incorporated in fibrin gels that trigger neovascularization for bone regeneration. ASC attachment to BCP60/40 and BCP20/80 within 30 min was similar (>93\%). After 11 days of culture BCP20/80-based composites showed increased alkaline phosphatase activity and DMP1 gene expression, but not RUNX2 and osteonectin expression, compared to BCP60/40-based composites. BCP20/80-based composites also showed enhanced expression of the vasculogenic markers CD31 and VEGF189, but not VEGF165 and endothelin-1. Collagen-1 and collagen-3 expression was similar in both composites. Fibrin degradation was increased in BCP20/80-based composites at day 7. In conclusion, BCP20/80-based composites showed enhanced osteogenic and vasculogenic differentiation potential compared to $\mathrm{BCP} 60 / 40$-based composites in vitro, suggesting that BCP20/80-based composites might be more promising for in vivo bone augmentation than BCP60/40-based composites.

\section{Introduction}

Bone tissue engineering has become a promising alternative for bone reconstruction. It is based on combinations of scaffolds, (stem) cells, and mechanical and/or chemical stimuli [1]. Autologous bone is the golden standard for clinical bone augmentation, for example, maxillary sinus floor elevation (MSFE) [2]. An alternative to the golden standard is biphasic calcium phosphate (BCP). BCPs are used as bone substitute materials for dental and orthopaedic applications. Ellinger et al. (1986) were the first to use the term BCP to describe bioceramics composed of hydroxyapatite
(HA) and $\beta$-tricalcium phosphate ( $\beta$-TCP) [3]. The chemical composition of $\mathrm{BCP}$ resembles the inorganic part of the natural bone matrix [4]. LeGeros and Daculsi reported in 1986 the first basic studies on the preparation of BCP and its in vitro properties $[5,6]$. Thereafter, there was a significant increase in manufacture and use of commercial BCP as bone substitute. HA is rigid, brittle, and hardly resorbed after application in, for example, MSFE, while $\beta$-TCP degrades faster and has a different resorption pattern [7]. For efficient scaffold remodelling, a BCP with an optimum ratio of HA and $\beta$-TCP is desired. BCP with a HA/ $\beta$-TCP ratio of $60 / 40$ (BCP60/40) is successfully applied clinically $[4,8,9]$, but 
the high percentage of HA may hamper efficient scaffold remodelling. Whether $\mathrm{BCP}$ with a $\mathrm{HA} / \beta$-TCP ratio of $20 / 80$ (BCP20/80) is more desirable compared to BCP60/40 is still unclear.

BCP supports attachment, proliferation, and osteogenic differentiation of progenitor cells, and can be combined with regeneration-competent stem cells, such as adipose stem cells (ASCs), to introduce osteogenic bioactivity $[10,11]$. Clinically relevant stem cell numbers with a high proliferative capacity can be easily extracted from human adipose tissue [12, 13]. ASCs have multilineage potential including the osteogenic lineage [14], and probably the endothelial lineage [15]. In the field of bone tissue engineering, ASCs have been successfully used for bone augmentation in MSFE [16].

Adequate vascularization is pivotal for cell survival of transplanted regeneration-competent stem cells in cell-based bone constructs. Osteogenesis and vasculogenesis are tightly coupled processes, and vascular development needs to be induced before osteogenesis can take place. This complexity has been a major challenge for engineering viable and functional bone grafts $[17,18]$. Bioscaffolds, like natural humanderived extracellular matrix scaffolds, enhance vascular development [19]. Another bioscaffold is fibrin, an insoluble, elastic protein playing a crucial role in blood clotting and wound healing. Cell-based bone constructs might be combined with bioscaffolds to induce vascular development.

BCP combined with bioscaffolds, like fibrin, has demonstrated its ability to fill bone defects and promote bone healing in animal and clinical studies [20-23]. Fibrin gel provides a biocompatible carrier for cellular function, survival, proliferation, and differentiation [24]. Enhanced bone formation has been shown after injection of mesenchymal stem cell(MSC-) seeded $\beta$-TCP in fibrin glue admixtures into the subcutaneous space on rat dorsa [24]. MSCs in fibrin gel used as a cell delivery system in vivo migrate out of the gel and invade ceramic scaffold [25].

A comparative study of BCP with different HA/TCP ratios in mandibular bone defects in minipigs showed that BCP20/80 results in similar bone formation as autologous bone after 52 weeks [26]. BCP scaffolds with a HA/ $\beta$ TCP ratio of $60 / 40$, a total porosity of $70 \%$ of which $50 \%$ were macropores (diameter $300-600 \mu \mathrm{m}$ ) and $30 \%$ were micropores (diameter $<10 \mu \mathrm{m}$ ) combined with fibrin sealant stimulated bone formation in animals and humans [2023]. A pore size of $300-400 \mu \mathrm{m}$ enhances bone formation and promotes neovascularization which is crucial before osteogenesis can take place in rats [27]. Therefore, in this study BCP biomaterials were used with a porosity of $90 \%$, and a pore size of $500-1000 \mu \mathrm{m}$. Human MSCs seeded on BCP60/40 or BCP20/80 incorporated subcutaneously in the back of immunodeficient mice showed the highest amount of bone filling in the pore space and even distribution throughout the entire porous structure of the implant in BCP20/80-loaded composites [28].

Since both osteogenic and vasculogenic differentiation potential of regeneration-competent ASCs seeded on BCP $60 / 40$ or BCP20/80 incorporated in fibrin gels is crucial for bone formation in cell-based bone constructs, we aimed to test the osteogenic and/or vasculogenic differentiation potential as well as degradation of composites consisting of human ASCs seeded on BCP60/40 or BCP20/80 incorporated in fibrin gels for bone regeneration. We hypothesized that BCP60/40- and BCP20/80-based composites would enhance osteogenic and vasculogenic differentiation potential of ASCs. We expected that ASCs in BCP20/80-based composites would result in earlier osteogenic differentiation compared to ASCs in BCP60/40-based composites since degradation rate of BCP20/80-based composites is expected to be higher. ASCs were seeded on BCP60/40 or BCP20/80, with similar pore size and porosity, and then incorporated in fibrin gels or directly incorporated in fibrin gels, and cultured for 11 days. Cell attachment to both BCPs was assessed $30 \mathrm{~min}$ after cell seeding, and cell proliferation, osteogenic and vasculogenic differentiation potential, and fibrin degradation were assessed up to 11 days of culture.

\section{Materials and Methods}

2.1. Biphasic Calcium Phosphate Scaffolds. Two different calcium phosphate scaffolds were used: (1) Straumann ${ }^{\circledR}$ BoneCeramic 60/40 (Institut Straumann AG, Basel, Switzerland), a porous BCP scaffold composed of $60 \% \mathrm{HA}$ and $40 \% \beta$ TCP (BCP60/40), and (2) Straumann BoneCeramic 20/80 (Institut Straumann AG, Basel, Switzerland), a porous BCP scaffold composed of $20 \% \mathrm{HA}$ and $80 \% \beta$-TCP (BCP20/80). To avoid differences in osteogenic and vasculogenic differentiation potential of ASCs seeded on BCP60/40 or BCP20/80 incorporated in fibrin gels caused by the BCP fabrication process, the two different BCPs were produced by the same company, and had similar pore size and porosity (Table 1).

2.2. Donors. Subcutaneous adipose tissue was harvested from residues of abdominal wall resections of five healthy female donors (aged 33, 40, 47, 50, and 54), who underwent elective abdominal wall correction at the Tergooi Hospital Hilversum and a clinic in Bilthoven, Netherlands. The Ethical Review Board of the VU Medical Center, Amsterdam, Netherlands, approved the protocol. Informed consent was obtained from all patients.

2.3. Isolation and Culture of Human ASCs. ASCs were isolated from the resection material as described with minor modifications [12]. In brief, adipose tissue was cut into small pieces and enzymatically digested with $0.1 \%$ collagenase A (Roche Diagnostics GmbH, Mannheim, Germany) for $45 \mathrm{~min}$ at $37^{\circ} \mathrm{C}$ in phosphate-buffered saline (PBS) containing $1 \%$ bovine serum albumin (Roche Diagnostics $\mathrm{GmbH}$ ) under continuous stirring. Ficoll ${ }^{\circledR}$ density-centrifugation step (Lymphoprep ${ }^{\text {TM }}$; Axis-Shield, Oslo, Norway; $1000 \times \mathrm{g}$ for $20 \mathrm{~min}, \rho=1.077 \mathrm{~g} / \mathrm{mL}$ Ficoll, osmolarity $280 \pm 15 \mathrm{mOsm}$ ) was performed to remove remaining erythrocytes from the stromal vascular fraction. After centrifugation, the resulting stromal vascular fraction pellet containing ASCs was resuspended in Dulbecco's modified Eagle's medium (Life Technologies $^{\mathrm{TM}}$ Europe BV, Bleiswijk, Netherlands), counted, frozen, and stored in liquid nitrogen until further use. Heterogeneity studies including cell characterization and 


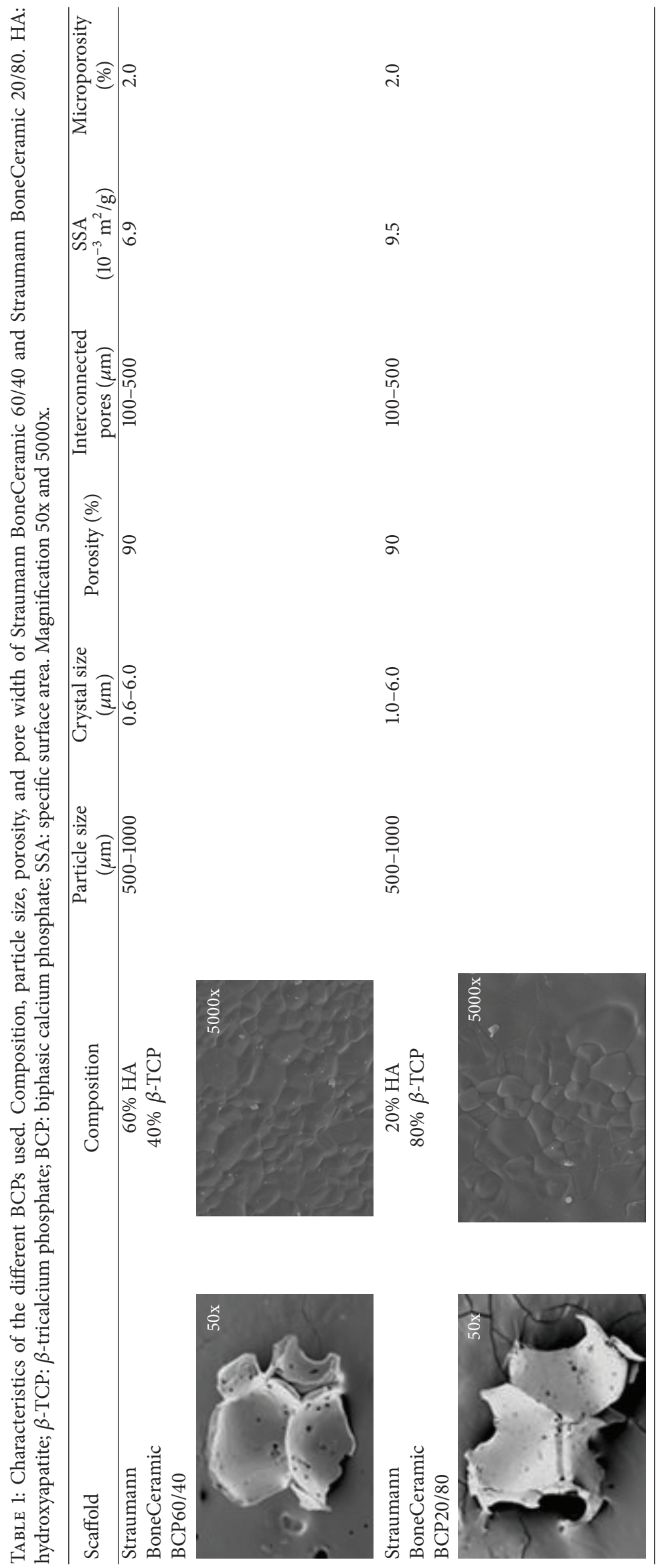




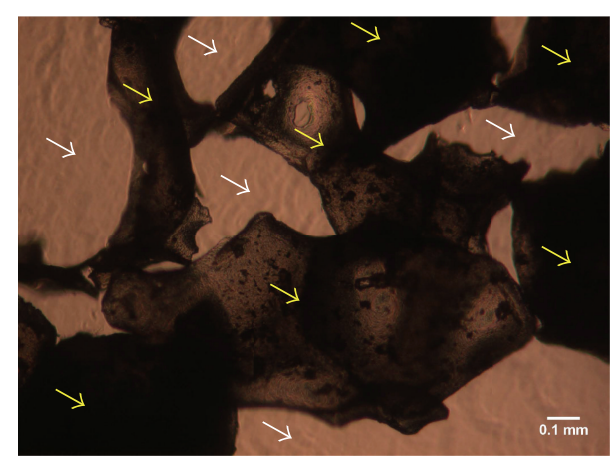

(a)

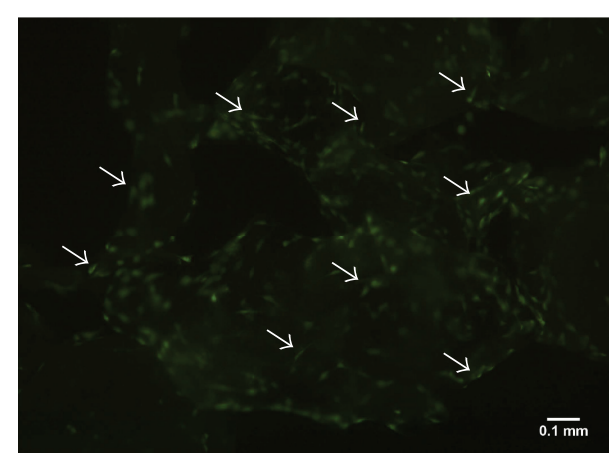

(b)

FIGURE 1: BCP-based composite consisting of ASCs seeded on BCP scaffold incorporated in fibrin gel immediately after preparation. (a) BCP60/40 particles in fibrin gel visualized by light microcopy. Yellow arrows, BCP; white arrows, fibrin gel. (b) ASCs visualized by fluorescence (green) on the same BCP60/40 particles in fibrin gel. White arrows: ASCs. Magnification 40x.

multipotent differentiation potential of these cells have been reported previously by our group [12].

Cryopreserved stromal vascular fraction-containing cell suspensions of the abovementioned donors were pooled and cultured in $\alpha$-Minimum Essential medium ( $\alpha$-MEM; Gibco, Life Technologies, Waltham, MA, USA) with 5\% platelet lysate (see below), $100 \mathrm{U} / \mathrm{mL}$ penicillin (SigmaAldrich, Hamburg, Germany), $100 \mu \mathrm{g} / \mathrm{mL}$ streptomycin sulfate (Sigma-Aldrich), and $10 \mathrm{IU} / \mathrm{mL}$ heparin (LEO Pharma $\mathrm{A} / \mathrm{S}$, Ballerup, Denmark) to prevent coagulation at $37^{\circ} \mathrm{C}$ in a humidified atmosphere with $5 \% \mathrm{CO}_{2}$. The medium was refreshed three times a week. After reaching confluency, cells were harvested by incubation with $0.25 \%$ trypsin (Gibco, Invitrogen, Waltham, MA, USA) and 0.1\% ethylenediaminetetraacetic acid (Merck, Darmstadt, Germany) in $\mathrm{PBS}$ at $37^{\circ} \mathrm{C}$, replated, cultured until passage $2(\mathrm{P} 2)$, and stored in liquid nitrogen until further use. Cryopreserved pooled ASCs-containing cell suspensions were thawed and seeded at $0.5 \times 10^{5}$ cells per T-225 culture flask (Greiner Bio-One, Kremsmuenster, Austria) in $\alpha$-MEM with $2 \%$ platelet lysate, antibiotics, and $10 \mathrm{IU} / \mathrm{mL}$ heparin. Cells were cultured until P3-P4, and used for preparation of composites (see below).

2.4. Platelet Lysate. Pooled platelet products from five donors were obtained from the Bloodbank Sanquin (Sanquin, Amsterdam, The Netherlands). Platelet lysate was obtained by lysing the platelets through temperature-shock by freezing at $-80^{\circ} \mathrm{C}$, thawing, and centrifugation at $600 \times \mathrm{g}$ for $10 \mathrm{~min}$ to eliminate remaining platelet fragments. The supernatant was added at $2 \%(\mathrm{v} / \mathrm{v})$ to the medium.

2.5. Fibrin Gel. Human fibrinogen plasminogen-depleted protein (Enzyme Research Laboratories, South Bend, IN, USA) was dissolved in Medium 199 (M199; Gibco, Life Technologies) with antibiotics at $37^{\circ} \mathrm{C}$ for $1 \mathrm{~h}$. Solubilized fibrinogen was filtered through a $0.2 \mu \mathrm{m}$ filter (Millipore, Amsterdam, Netherlands), and the concentration measured with a Synergy $\mathrm{HT}^{\circledR}{ }^{\circledR}$ spectrophotometer (BioTek Instruments Inc., Winooski, VT, USA). To prepare fibrin gel, $2 \mathrm{mg} / \mathrm{mL}$ fibrinogen solution was polymerized with $1.0 \mathrm{IU} / \mathrm{mL}$ bovine $\alpha$-thrombin (Enzyme Research Laboratories, South Bend, IA, USA) in a buffer containing $50 \mathrm{mM}$ sodium citrate, $0.2 \mathrm{M}$ sodium chloride, and $0.1 \%$ polyethylene glycol-8000, for $1 \mathrm{~h}$ at room temperature followed by $1 \mathrm{~h}$ at $37^{\circ} \mathrm{C}$, and used for fibrin coating of polystyrene 48-well culture plates (Cellstar, Greiner Bio-One International GmbH, Frickenhausen, Germany), as well as for preparation of BCP60/40- and BCP20/80-based composites, and ASCs in gels (see below).

2.6. Preparation and Culture of Composites. Cultured ASCs were washed three times with PBS to remove platelet lysate, and seeded on either BCP60/40 or BCP20/80 and then incorporated in fibrin gels to prepare BCP60/40- and BCP20/80based composites, or directly incorporated in fibrin gels. Twenty-five to $30 \mathrm{mg}$ BCP60/40 or BCP20/80 was hydrated in PBS for $30 \mathrm{~min}$. After PBS removal, $1 \times 10^{5}$ ASCs in $100 \mu \mathrm{L} \alpha$-MEM were allowed to attach for $30 \mathrm{~min}$ at room temperature. Unattached cells were counted using a counting chamber (Optik Labor, Lancing, UK). Cell-seeded BCP scaffolds were embedded in fibrin gel and placed on fibrin-coated plates. Immediately after preparation, some composites were used for light microscopy to show the BCP particles in fibrin gel (Figure 1(a)), and to visualize ASCs on these particles in gel by cytotracker green (Invitrogen) according to the manufacturer's instructions (Figure $1(\mathrm{~b})$ ). As a control, $1 \times 10^{5}$ ASCs were embedded in fibrin and placed on fibrin-coated plates.

BCP60/40- and BCP20/80-based composites, and ASCs in gels were cultured in $\alpha$-MEM without phenol red (Gibco, Life Technologies, Waltham, MA, USA) with $2 \%$ platelet lysate, antibiotics, $50 \mu \mathrm{g} / \mathrm{mL}$ 2-phospho-L-ascorbic acid trisodium salt (Sigma-Aldrich, Steinheim, Germany), and $10 \mathrm{IU} / \mathrm{mL}$ heparin for 11 days at $37^{\circ} \mathrm{C}$ in a humidified atmosphere with $5 \% \mathrm{CO}_{2}$. Medium was refreshed after 7 days.

2.7. Human ASC Proliferation in Composites and Fibrin Gels. Proliferation was assessed by determining cell number in BCP60/40- and BCP20/80-based composites and fibrin gels 
at days 1 and 11 by using alamarBlue ${ }^{\circledR}$ fluorescent assay (Invitrogen, Frederick, MD, USA), according to the manufacturer's instructions. We found a linear relationship between alamarBlue fluorescence and cell number (data not shown). Fluorescence was read in medium samples at $530 \mathrm{~nm}$ with a Synergy HT spectrophotometer.

2.8. Alkaline Phosphatase Activity. Alkaline phosphatase (ALP) activity was measured to assess the osteoblastic phenotype of ASCs in BCP60/40- and BCP20/80-based composites and fibrin gels after 1 and 11 days of culture. Both composites and fibrin gels were transferred to 24-well culture plates (Cellstar), washed with PBS, crushed in $300 \mu \mathrm{L}$ Milli-Q water, and stored at $-20^{\circ} \mathrm{C}$ prior to further use. ALP activity was measured in the cell lysate using 4-nitrophenyl phosphate disodium salt (Merck, Darmstadt, Germany) as a substrate at $\mathrm{pH} 10.3$, according to the method described by Lowry [29]. The absorbance was read at $405 \mathrm{~nm}$ with a Synergy HT spectrophotometer. ALP activity was expressed as $\mu \mathrm{M}$ per ng DNA.

2.9. Analysis of Gene Expression. At days 1, 7, and 11 of culture, BCP60/40- and BCP20/80-based composites and fibrin gels were transferred to 24-well culture plates, washed with PBS, crushed in $750 \mu \mathrm{L}$ TRIzol ${ }^{\circledR}$ reagent (Life Technologies, Waltham, MA, USA), and stored at $-20^{\circ} \mathrm{C}$ until further use. Total RNA was isolated using RNeasy ${ }^{\circledR}$ Mini Spin Columns (Qiagen Sciences, Gaithersburg, MD, USA) according to the manufacturer's instructions, and stored at $-20^{\circ} \mathrm{C}$ until further use. Complementary DNA (cDNA) synthesis was performed using SuperScript ${ }^{\circledR}$ VILO $^{\text {TM }}$ cDNA Synthesis kit (Invitrogen, Life Technologies, Carlsbad, CA, USA), with $10.5 \mu \mathrm{L}$ total RNA in a $15 \mu \mathrm{L}$ reaction mix containing $3 \mu \mathrm{L}$ VILO Reaction Mix and $1.5 \mu \mathrm{L}$ SuperScript Enzyme Mix in a thermocycler GeneAmp ${ }^{\circledR}$ PCR System 9700 PE (Applied Biosystems, Foster City, CA, USA). cDNA was stored at $-20^{\circ} \mathrm{C}$ prior to quantitative real-time PCR (qPCR) analysis, and diluted 5x for gene expression analysis. qPCR reactions were performed using $2 \mu \mathrm{L}$ cDNA per reaction $(10 \mu \mathrm{L}$ total reaction volume containing $10 \mathrm{pmol}$ of each primer) and LightCycler ${ }^{\circledR} 480$ SYBR $^{\circledR}$ Green I Mastermix (Roche Diagnostics, Mannheim, Germany) in a LightCycler 480 (Roche Diagnostics). qPCR conditions for all genes were as follows: $10 \mathrm{~min}$ preincubation at $95^{\circ} \mathrm{C}$, followed by 35 cycles of amplification at $95^{\circ} \mathrm{C}$ for $2 \mathrm{~s}$, $56^{\circ} \mathrm{C}$ for $8 \mathrm{~s}, 72^{\circ} \mathrm{C}$ for $10 \mathrm{~s}$, and $82^{\circ} \mathrm{C}$ for $5 \mathrm{~s}$, after which melting curve analysis was performed. With Light $\mathrm{Cycler}^{\circledR}$ software (version 1.2), crossing points were assessed and plotted versus the serial dilution of known concentrations of the standard (human primary bone: $2.5-0.004 \mathrm{ng} / \mu \mathrm{L}$ ). A human trabecular bone sample (surgical waste) was taken from the femoral head, immediately (within $1 \mathrm{~h}$ ) after hip surgery for cox-arthrosis, and used as positive control. The protocol was approved by the Ethical Review Board of the VU University Medical Center. PCR efficiency $(E)$ was obtained by using the formula $E=10^{-1 / \text { slope }}$. Data were used only if $E=1.85-$ 2.0. For gene expression analysis, the values of target gene expression were normalized to YWHAZ housekeeping gene expression to obtain relative gene expression. qPCR was used to assess expression of the following genes: KI67, runt-related transcription factor-2 (RUNX2), osteonectin (ON), dentin matrix acidic phosphoprotein-1 (DMP1), collagen-1 (COL1), collagen-3 (COL3), cluster of differentiation-31 (CD31), vascular endothelial growth factor-165 (VEGF165), vascular endothelial growth factor-189 (VEGF189), and endothlin-1 $(E D N 1)$. Primer sequences used for qPCR are listed in Table 2.

2.10. Fibrin Degradation. Fibrin degradation products were quantified using an enzyme-linked immunosorbent assay as described [30]. Briefly, the antibody fibrin degradation products-14 (FDP-14; TNO, Quality of Life, Leiden, Netherlands) recognizing different epitopes of fibrin degradation products was used as catching antibody. Fibrin degradation product concentrations in the medium of BCP60/40- and BCP20/80-based composites and fibrin gels were investigated after 1, 4, 7, and 11 days of culture, and Biopool standard (Trinity Biotech, Wicklow, Ireland) was used as a reference. Finally, monoclonal antibody D-dimer-13 (DD-13; TNO) labeled with horseradish peroxidase was used as tagging antibody. The coloring reaction was performed using $3,3^{\prime}, 5,5^{\prime}-$ tetramethybenzidine (Sigma-Aldrich, St. Louis, MO, USA) and stopped with $1 \mathrm{M} \mathrm{H}_{2} \mathrm{SO}_{4}$. The optical density was read at $450 \mathrm{~nm}$ with Synergy HT spectrophotometer.

2.11. Statistical Analysis. Data were obtained from quadruple cultures of three independent experiments for BCP60/40based composites and fibrin gels, and two independent experiments for BCP20/80-based composites. Data are presented as mean \pm SEM. Two-tailed unpaired $t$-test was used to compare cell attachment to BCP60/40 and BCP20/80. Differences in alamarBlue fluorescence, ALP activity, and gene expression between BCP60/40- and BCP20/80-based composites and fibrin gels were tested with one-way variance of analysis (ANOVA). To compare fibrin degradation, oneway repeated measures ANOVA was performed. Differences were considered significant if $p<0.05$. Statistical analysis was performed using $\mathrm{IBM}^{\circledR}$ SPSS ${ }^{\circledR}$ Statistics version 21 software package (SPSS Inc., Chicago, IL, USA) and GraphPad Prism ${ }^{\circledR}$ 5.0 (GraphPad Software Inc., La Jolla, CA, USA).

\section{Results}

3.1. Cell Attachment to BCP60/40 and BCP20/80. Cell attachment to BCP60/40 and BCP20/80 was similar (BCP60/40: $92730 \pm 640$, mean cell number \pm SEM, $n=60$ samples; BCP20/80: $98100 \pm 350, n=30$ samples). After incorporation of cell-seeded BCP in fibrin gel, microscopic observations showed migration of cells towards the fibrin gel in both composites at day 1 (data not shown). The exact number of migrated cells could not be determined with the currently available assays. Future studies have to reveal the precise contribution of cells on BCP and migrated cells to the osteogenic and vasculogenic differentiation potential of both composites.

\subsection{Increased Cell Proliferation and ALP Activity in BCP60/} 40- and BCP20/80-Based Composites. Cell proliferation in BCP60/40- and BCP20/80-based composites was similar, and 1.4-1.5-fold higher compared to fibrin gels (Figure 2(a)). 
TABLE 2: Primer sequences for determination of osteogenic and vasculogenic differentiation potential through PCR. YWHAZ: tyrosine 3-monooxygenase/tryptophan 5-monooxygenase activation protein, zeta; KI67: proliferation marker; RUNX2: runt-related transcription factor-2; ON: osteonectin; DMP1: dentin matrix acidic phosphoprotein-1; COL1: collagen-1; COL3: collagen-3; CD31: cluster of differentiation31; VEGF165: vascular endothelial growth factor-165; VEGF189: vascular endothelial growth factor-189; EDN1: endothlin-1; bp: base pairs.

\begin{tabular}{|c|c|c|c|c|}
\hline Target gene & & Oligonucleotide sequence & Product size (bp) & Annealing temperature $\left({ }^{\circ} \mathrm{C}\right)$ \\
\hline \multirow{2}{*}{ YWHAZ } & Forward & $5^{\prime}$ gATgAAgCCATTgCTGAACTTg $3^{\prime}$ & \multirow{2}{*}{229} & \multirow{2}{*}{56} \\
\hline & Reverse & 5' CTATTTgTgggACAgCATggA 3' & & \\
\hline \multirow{2}{*}{ KI67 } & Forward & $5^{\prime}$ CCCTCAgCAAgCCTgAgAA $3^{\prime}$ & \multirow{2}{*}{202} & \multirow{2}{*}{56} \\
\hline & Reverse & $5^{\prime}$ AgAggCgTATTAggAggCAAg 3' & & \\
\hline \multirow{2}{*}{ RUNX2 } & Forward & $5^{\prime}$ ATgCTTCATTCgCCTCAC $3^{\prime}$ & \multirow{2}{*}{156} & \multirow{2}{*}{56} \\
\hline & Reverse & $5^{\prime}$ ACTgCTTgCAgCСТTAAAT $3^{\prime}$ & & \\
\hline \multirow{2}{*}{ ON } & Forward & $5^{\prime}$ CTgTCCAggTggAAgTAgg 3' & \multirow{2}{*}{233} & \multirow{2}{*}{56} \\
\hline & Reverse & $5^{\prime}$ gTggCAggAAgAgTCgAAg $3^{\prime}$ & & \\
\hline \multirow{2}{*}{$D M P 1$} & Forward & $5^{\prime}$ TAggCTAgCTggTggCTTCT $3^{\prime}$ & \multirow{2}{*}{375} & \multirow{2}{*}{56} \\
\hline & Reverse & $5^{\prime}$ AACTCggAgCCgTCTCCAT $3^{\prime}$ & & \\
\hline \multirow{2}{*}{ COL1 } & Forward & $5^{\prime}$ TCCggCTCCTgCTCСТCTTA $3^{\prime}$ & \multirow{2}{*}{336} & \multirow{2}{*}{56} \\
\hline & Reverse & $5^{\prime}$ ggCCAgTgTCТСССТTg $3^{\prime}$ & & \\
\hline \multirow{2}{*}{ COL3 } & Forward & $5^{\prime}$ gATCCgTTCTCTgCgATgAC $3^{\prime}$ & \multirow{2}{*}{279} & \multirow{2}{*}{56} \\
\hline & Reverse & 5' AgTTCTgAggACCAgTAggg 3' & & \\
\hline \multirow{2}{*}{ CD31 } & Forward & $5^{\prime}$ AACAggAgggAgAgTATTACTg $3^{\prime}$ & \multirow{2}{*}{236} & \multirow{2}{*}{56} \\
\hline & Reverse & $5^{\prime}$ TggTACTgCTggCCTggA $3^{\prime}$ & & \\
\hline \multirow{2}{*}{ VEGF165 } & Forward & $5^{\prime}$ ATCTTCAAgCCATCCTgTgTgC $3^{\prime}$ & \multirow{2}{*}{224} & \multirow{2}{*}{56} \\
\hline & Reverse & 5' CAAggCCCACAgggATTTTC 3' & & \\
\hline \multirow{2}{*}{ VEGF189 } & Forward & $5^{\prime}$ ATCTTCAAgCCATCCTgTgTgC $3^{\prime}$ & \multirow{2}{*}{289} & \multirow{2}{*}{56} \\
\hline & Reverse & 5' CACAgggAACgCTCCAggAC $3^{\prime}$ & & \\
\hline \multirow{2}{*}{ EDN1 } & Forward & $5^{\prime}$ gTTTgTggCTTgCCAAggA $3^{\prime}$ & \multirow{2}{*}{207} & \multirow{2}{*}{56} \\
\hline & Reverse & $5^{\prime}$ ACgTgCTCgggAgTgTTgA $3^{\prime}$ & & \\
\hline
\end{tabular}

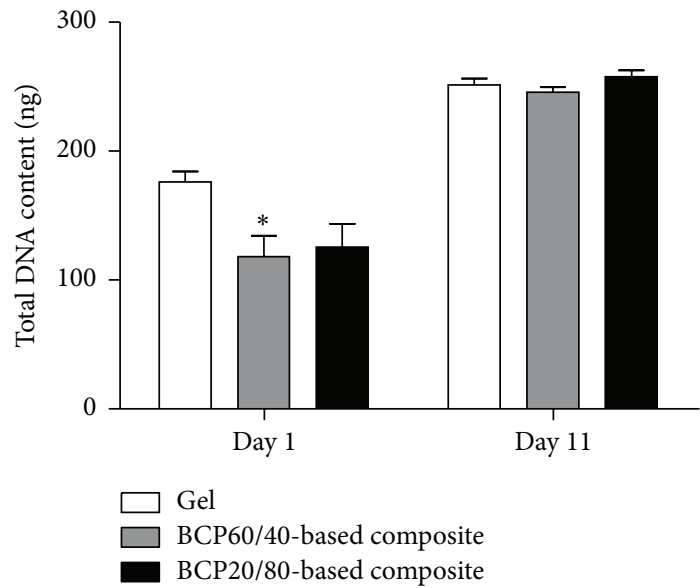

(a)

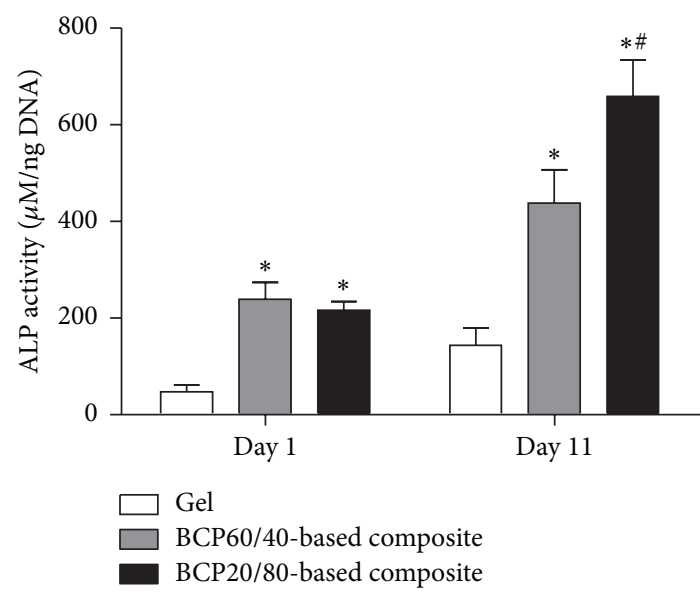

(b)

FIGURE 2: ASC proliferation and osteogenic differentiation in BCP60/40- and BCP20/80-based composites and fibrin gels at day 1 and 11 of culture. (a) Total DNA content in BCP60/40- and BCP20/80-based composites and fibrin gels. The increase in total DNA content from day 1 to day 11 was significantly higher in BCP60/40- and BCP20/80-based composites compared to fibrin gels, indicating similar proliferation in both composites, but increased proliferation in both composites compared to fibrin gels. (b) ALP activity in BCP60/40- and BCP20/80-based composites and fibrin gels. BCP20/80-based composites showed higher ALP activity compared to BCP60/40-based composites at day 11. ALP activity of both BCP60/40 - and BCP20/80-based composites was higher compared to fibrin gels at days 1 and 11 . Values are mean \pm SEM $(n=8-12) .{ }^{*}$ Significant effect of BCP60/40- or BCP20/80-based composites compared to fibrin gels, $p<0.05$. ${ }^{\#}$ Significantly different from BCP60/40-based composites, $p<0.05$. BCP, biphasic calcium phosphate; ALP, alkaline phosphatase. 
BCP20/80-based composites showed a 1.5-fold increased ALP activity compared to BCP60/40-based composites at day 11 (Figure 2(b)). ALP activity in both composites was higher compared to fibrin gels at days 1 (4.6-5.0-fold) and 11 (3.14.6-fold; Figure 2(b)).

3.3. Enhanced Osteogenic Differentiation Potential of BCP20/80-Based Composites. No differences were observed in gene expression of the proliferation marker KI67 in both composites at all time points. KI67 gene expression was increased in BCP60/40- (3.0-fold) as well as BCP20/80based composites (4.0-fold) compared to fibrin gels at day 11 (Figure 3(a)). Gene expression of the early osteogenic differentiation marker RUNX2 in both composites was similar as well as compared to fibrin gels at all time points (Figure 3(b)). Expression of the early-to-late osteogenic differentiation marker $O N$ in both composites was also similar at all time points (Figure 3(c)). BCP60/40-based composites resulted in decreased $O N$ gene expression compared to fibrin gels at days 1 (0.2-fold) and 7 (0.1-fold). ON expression in BCP20/ 80-based composites was also decreased compared to fibrin gels at day 7 (0.2-fold; Figure 3(c)). Gene expression of the late osteogenic differentiation marker DMP1 in BCP20/ 80 -based composites was increased compared to BCP60/40based composites at days 1 (2.1-fold) and 11 (9.2-fold). DMP1 expression in BCP20/80-based was also increased compared to fibrin gels at days 1 (6.8-fold) and 11 (10.4-fold; Figure $3(\mathrm{~d})$ ). The extracellular matrix proteins COL1 and COL3 are expressed in osteogenesis and vasculogenesis. COL1 gene expression was similar in both composites as well as compared to fibrin gels at all time points (Figure 3(e)). BCP60/40- and BCP20/80-based composites showed no significant differences in $C O L 3$ gene expression at all time points (Figure 3(f)). COL3 gene expression in BCP60/40based composites was decreased compared to fibrin gels at day 7 (0.2-fold; Figure 3(f)).

3.4. Enhanced Vasculogenic Differentiation Potential of BCP20/80-Based Composites. BCP20/80-based composites showed increased CD31 gene expression compared to BCP60/40-based composites at day 11 (2.8-fold), as well as compared to fibrin gels (6.2-fold; Figure 4(a)). CD31 gene expression in both composites was decreased (2.3-2.8fold) compared to fibrin gels at day 1 (Figure 4(a)). Gene expression of VEGF165 in both composites was similar, as well as compared to fibrin gels at all time points (Figure 4(b)). BCP20/80-based composites showed increased VEGF189 gene expression at days 1 (3.6-fold) and 7 (2.6-fold) compared to BCP60/40-based composites, as well as compared to fibrin gels at day 11 (5.5-fold; Figure 4(c)). Gene expression of EDN1 in both composites showed no significant differences at all time points (Figure 4(d)). BCP60/40-based composites resulted in decreased EDN1 gene expression compared to fibrin gels at day 7 (0.2-fold; Figure 4(d)).

3.5. Differences in Fibrin Degradation between Composites. A decreased concentration of fibrin degradation products in the medium of BCP20/80-based composites compared to fibrin gels was observed at day 1 (0.02-fold; Figure 5).
The degradation products concentration was increased in BCP20/80-based composites compared to BCP60/40-based composites (1.7-fold) and fibrin gels at day 7 (1.8-fold), but reached similar levels at day 11 .

\section{Discussion}

This study aimed to test the osteogenic and/or vasculogenic differentiation potential as well as degradation of composites consisting of human ASCs seeded on BCP60/40 or BCP20/80 incorporated in fibrin gels for bone regeneration. We found that (i) ASC attachment to both BCPs was similar; (ii) proliferation in BCP60/40- and BCP20/80based composites was similar, but higher compared to fibrin gels; (iii) BCP20/80-based composites showed higher ALP activity compared to BCP60/40-based composites; (iv) gene expression of the late osteogenic marker DMP1 in BCP20/80based composites was increased compared to BCP60/40based composites as well as to fibrin gels; (v) higher gene expression of the vasculogenic markers CD31 and VEGF189 was seen in BCP20/80-based composites compared to both BCP60/40-based composites and fibrin gels. Therefore, our results showed enhanced osteogenic and vasculogenic differentiation potential in BCP20/80-based composites compared to $\mathrm{BCP} 60 / 40$-based composites in vitro, suggesting that BCP20/80-based composites might be more promising for in vivo bone augmentation than BCP60/40-based composites.

We found that ASC attachment to both BCPs was similar, as shown earlier [31], indicating that different HA/ $\beta$-TCP ratios of BCP did not affect ASC attachment. To ensure cell survival, proliferation, and differentiation of transplanted cell-seeded scaffolds after implantation, adequate nutrient and oxygen supply is crucial. A composite will easily become hypoxic after implantation in the body. ASCs cultured on fibrin gel-coated plates show enhanced proliferation under severe hypoxic conditions ( $1 \%$ oxygen) compared to conventional oxygen conditions ( $20 \%$ oxygen) [32]. Therefore, enhanced proliferation in both composites might be explained by a stimulatory effect of the BCP scaffold [33], and/or a hypoxic microenvironment, which likely also occurs after in vivo implantation.

The concept that degradation by-products can influence stem cell function, including cell fate decisions, is emerging [34]. TCP supports cell ingrowth and promotes osteogenic differentiation of osteoprogenitor cells [35]. The extent of dissolution of $\mathrm{BCP}$ depends on the HA/ $\beta$-TCP ratio; the lower the ratio, the more the dissolution [36]. We found higher ALP activity, indicating enhanced osteogenic differentiation in BCP20/80-based composites compared to BCP60/40-based composites. This can be explained by the low $\mathrm{HA} / \beta$-TCP ratio in BCP20/80 compared to BCP60/40, indicating higher $\mathrm{Ca}^{2+}$ ion release in BCP20/80-based composites which is crucial for bone formation. Degradation of surrounding material, that is, fibrin gel, can lead to celltraction forces, which are crucial for osteogenic differentiation of human MSCs in a three-dimensional context and might explain the acceleration in osteogenic differentiation in both composites and fibrin gels [37]. This speculation is 


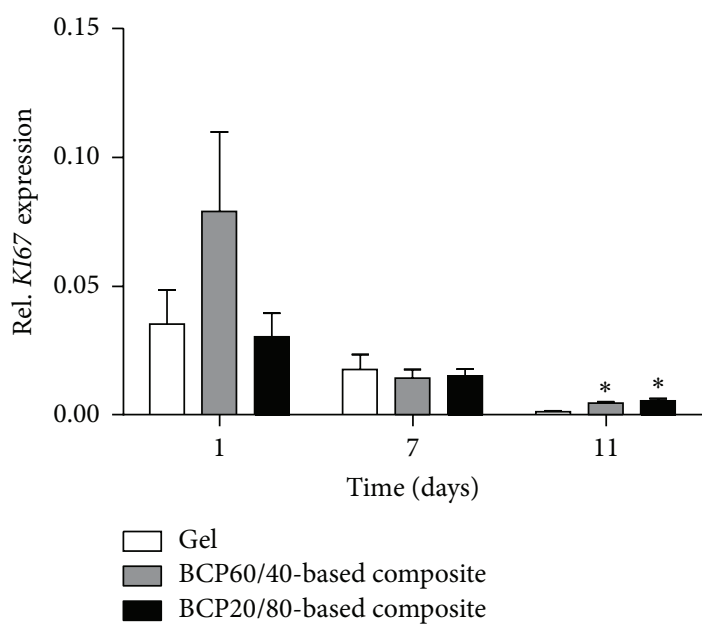

(a)

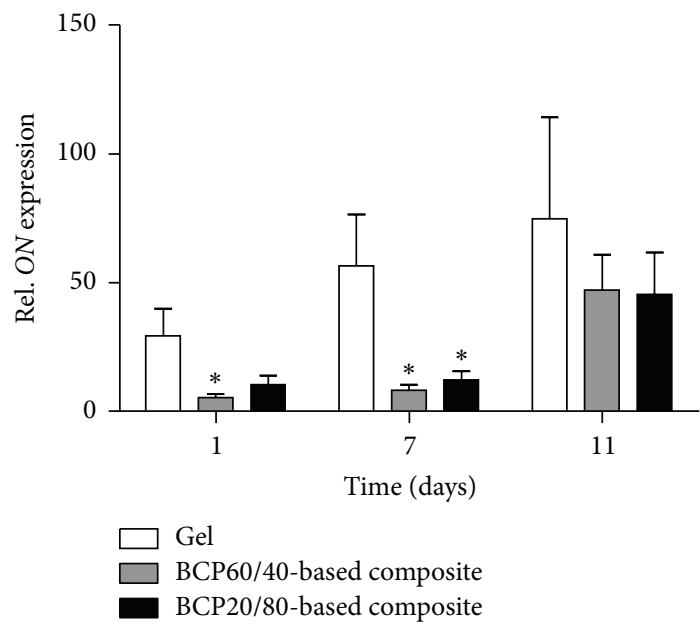

(c)

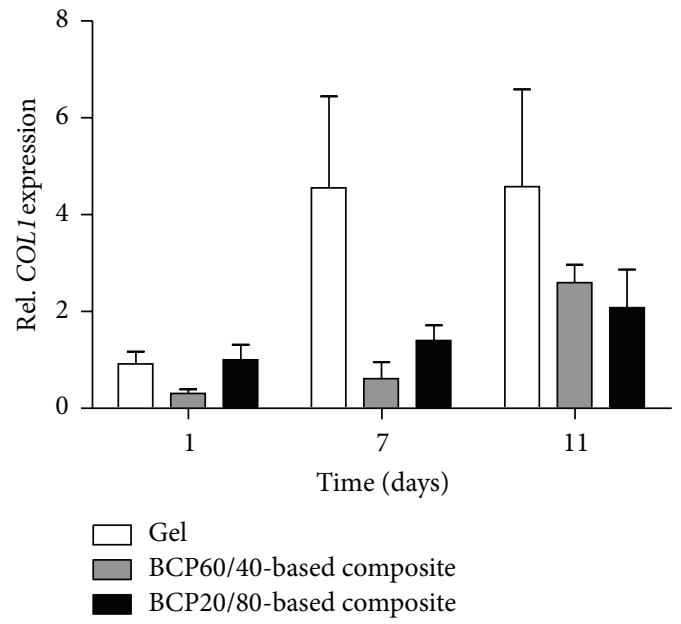

(e)

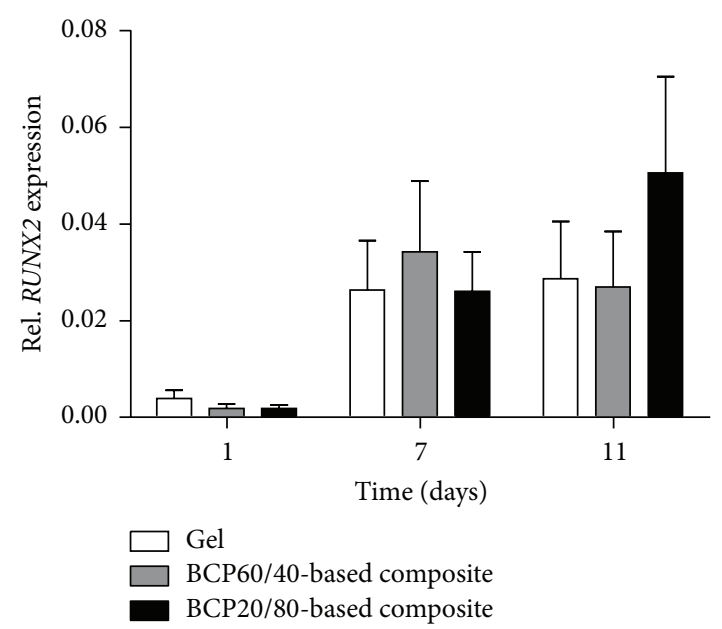

(b)

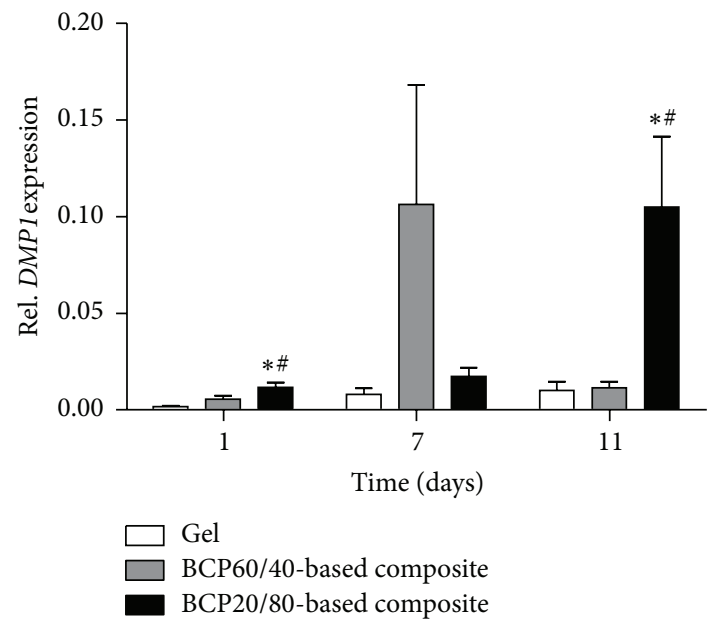

(d)

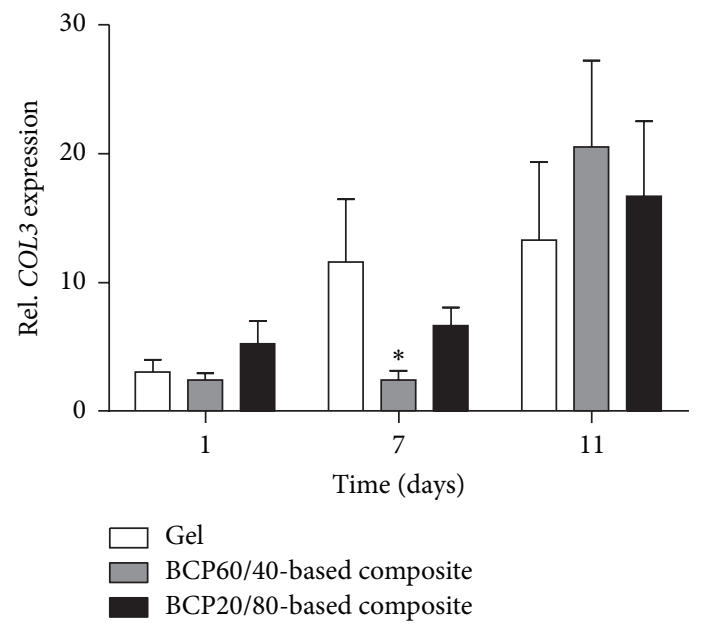

(f)

FIGURE 3: Gene expression of the proliferation marker KI67 and osteogenic differentiation markers RUNX2, ON, DMP1, COL1, and COL3 in BCP60/40 - and BCP20/80-based composites and fibrin gels at days 1, 7, and 11 of culture. (a) BCP60/40- and BCP20/80-based composites showed increased KI67 gene expression compared to fibrin gels at day 11. (b) RUNX2 gene expression was similar for BCP60/40- and BCP20/80-based composites and fibrin gels at all time points. (c) BCP60/40- and BCP20/80-based composites showed similar ON gene expression at all time points. (d) BCP20/80-based composites showed increased DMP1 gene expression compared to BCP60/40-based composites, as well as to fibrin gels at days 1 and 11. (e, f) Gene expression of COL1 and COL3 in BCP60/40- and BCP20/80-based composites was similar at all time points. Values are mean \pm SEM $(n=7-12) .{ }^{*}$ Significant effect of BCP60/40- or BCP20/80-based composites compared to fibrin gels, $p<0.05$. "Significantly different from BCP60/40-based composites, $p<0.05$. BCP, biphasic calcium phosphate; KI67, proliferation marker; RUNX2, runt-related transcription factor-2; ON, osteonectin; DMP1, dentin matrix acidic phosphoprotein-1; COL1, collagen-1; COL3, collagen-3. 


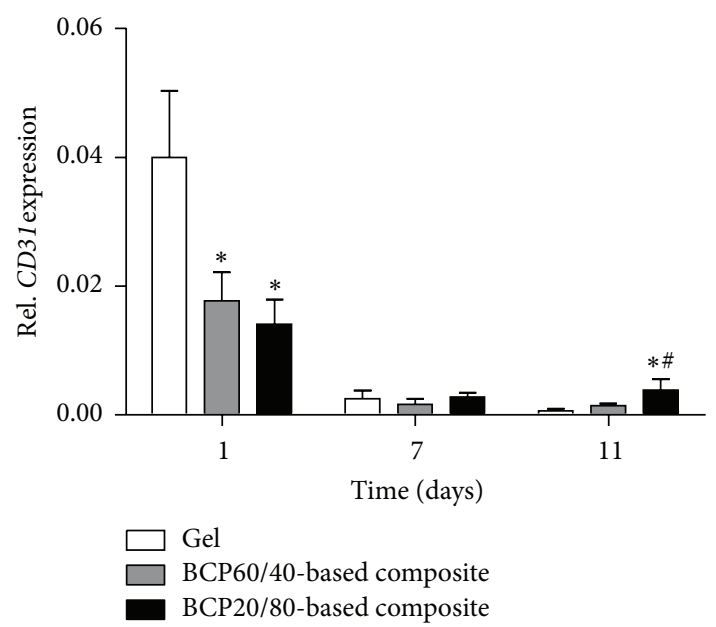

(a)

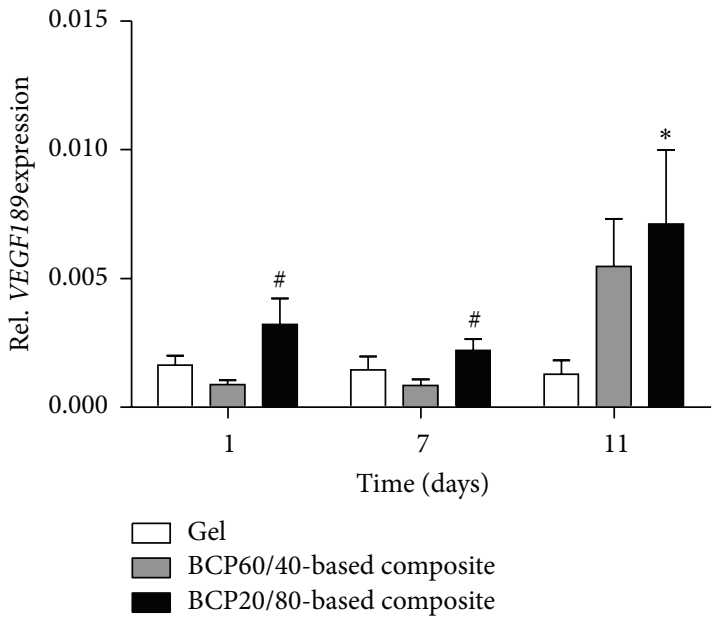

(c)

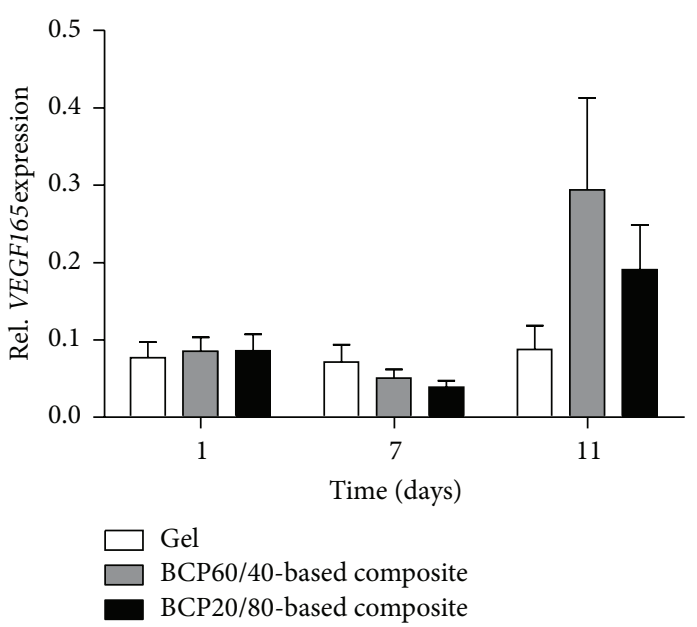

(b)

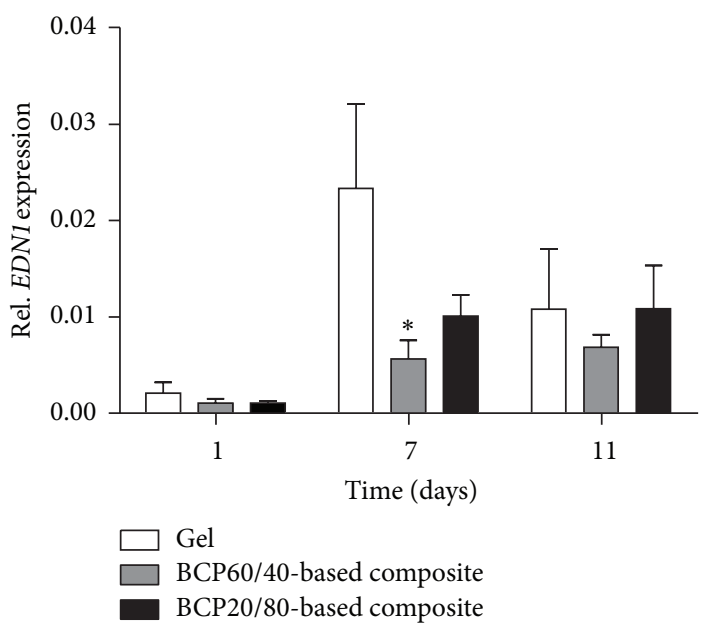

(d)

FIGURE 4: Gene expression of the vasculogenic differentiation markers CD31, VEGF165 and VEGF189, and EDN1 in BCP60/40- and BCP20/80based composites, and fibrin gels at days 1, 7, and 11 of culture. (a) BCP20/80-based composites showed increased CD31 gene expression compared to BCP60/40-based composites at day 11, as well as to fibrin gels. (b) BCP60/40- and BCP20/80-based composites demonstrated similar VEGF165 gene expression at all time points. (c) BCP20/80-based composites showed increased VEGF189 gene expression compared to BCP60/40-based composites at days 1 and 7. (d) BCP60/40- and BCP20/80-based composites showed similar EDN1 gene expression at all time points. Values are mean \pm SEM $(n=5-12)$. ${ }^{*}$ Significant effect of BCP60/40- or BCP20/80-based composites compared to fibrin gels, $p<0.05$. "Significantly different from BCP60/40-based composites, $p<0.05$. BCP, biphasic calcium phosphate; CD31, cluster of differentiation-31; VEGF165, vascular endothelial growth factor-165; VEGF189, vascular endothelial growth factor-189; EDN1, endothelin-1.

consistent with our fibrin degradation products data showing increased fibrin degradation in BCP20/80-based composites compared to BCP60/40-based composites at day 7. We found higher expression of the late stage osteogenic differentiation marker DMP1, but similar expression of early and early-tolate osteogenic differentiation markers in BCP20/80-based composites compared to BCP60/40-based composites, suggesting that BCP20/80-based composites were in a later stage of osteogenic commitment compared to BCP60/40-based composites as well as to fibrin gels. Therefore, BCP20/80based composites seem promising for implantation in vivo for enhanced bone formation.

Vascular development needs to be induced prior to osteogenesis. CD31 is expressed on the cell surface of endothelial and hematopoietic cells. BCP20/80-based composites showed increased CD31 expression compared to BCP60/40based composites indicating higher vessel-forming potency. During culture, CD31 expression decreased, while VEGF165, VEGF189, and EDN1 expression increased over time in both composites. The high expression of these vasculogenic genes indicates increased vasculogenic differentiation potential of both composites, although CD31 expression decreased, which suggests that the number of endothelial progenitor cells had decreased over time. VEGF probably functions as a hypoxia-inducible angiogenic factor [38]. We found increased expression of the vasculogenic marker VEGF189 in BCP20/80-based composites compared to fibrin gels. Therefore, BCP20/80-based composites might offer a hypoxic microenvironment for the ASCs, resulting in increased VEGF expression. Endothelin-1 is a potent vasoconstrictor and 


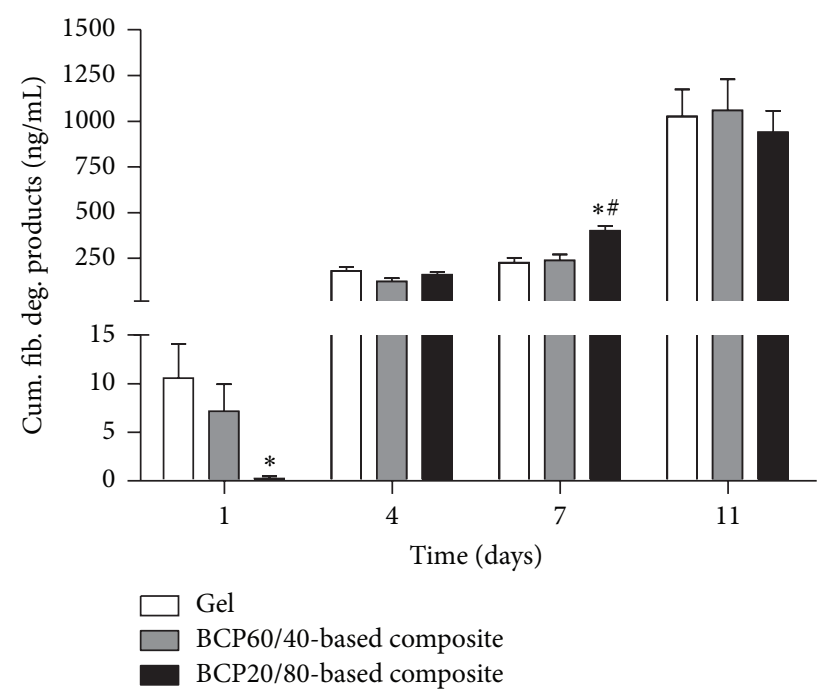

FIGURE 5: Differences in fibrin degradation of BCP60/40- and BCP20/80-based composites and fibrin gels. BCP60/40- and BCP20/80-based composites degradation was similar at day 11. BCP20/80-based composites resulted in increased concentration of fibrin degradation products compared to BCP60/40-based composites at day 7 of culture, as well as to fibrin gels. Values are mean \pm SEM $(n=8-12)$. * Significant effect of BCP60/40- or BCP20/80based composites compared to fibrin gels, $p<0.05$. " Significantly different from BCP60/40-based composites, $p<0.05$. BCP, biphasic calcium phosphate; cum, cumulative; fib, fibrin; deg, degradation.

has been identified originally in vascular endothelial cells. In osteoblasts, it stimulates inorganic phosphate transport, which is important for bone matrix calcification [39]. EDN1 expression was increased during culture in both BCP60/40and BCP20/80-based composites, which indicates enhanced vasculogenic and osteogenic differentiation potential. Future studies are needed to verify possible differences in blood vessel and bone formation using composites with ASCs, BCPs with different $\mathrm{HA} / \beta$-TCP ratios, and fibrin gels in vivo.

The stem cell-matrix interface is a complex, dynamic microenvironment in which the cell and the material cooperatively dictate one another's fate and regulate stem cell differentiation [37]. Changes in fibrin composition will create different matrix stiffness and architectural properties, which will have impact on cellular response. Stem cells are extremely sensitive to elasticity of their surrounding matrix, through mechanosensitive ion channels, focal adhesions, cell surface receptors, actin cytoskeleton, and cellcell adhesions, and they respond dramatically in lineage to the matrix presented [40]. Understanding the mechanisms of cellular sensory capabilities of ASCs will be relevant for application of our composites in tissue engineering. Fibrin remodelling was increased in BCP20/80-based composites compared to BCP60/40-based composites, but reached a similar level at the end of culture. The difference in fibrin remodelling possibly results in differences in cellular behaviour. The increase in fibrin degradation products during culture suggests dissolution of fibrin. After implantation of BCP60/40- and BCP20/80-based composites in the body,

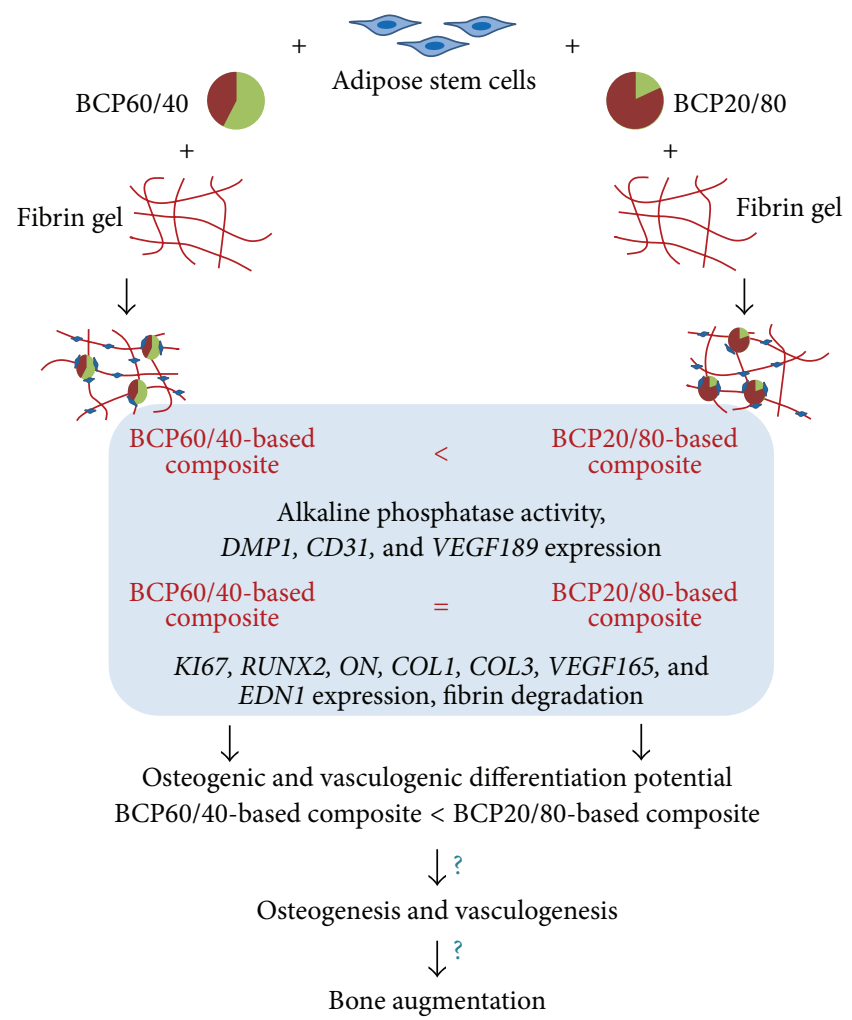

HA
$\beta$-TCP

Figure 6: Development of BCP60/40-based composites and BCP20/80-based composites. Human adipose stem cells were seeded on BCP $60 / 40$ or BCP20/80 and incorporated in fibrin gels. BCP20/80-based composites showed enhanced osteogenic differentiation and vasculogenic potential compared to BCP60/40based composites in vitro. =, similar in both composites; <, higher in BCP20/80-based composites compared to BCP60/40-based composites; HA, hydroxyapatite; $\beta$-TCP, $\beta$-tricalcium phosphate; KI67, proliferation marker; $R U N X 2$, runt-related transcription factor-2; $O N$, osteonectin; $D M P 1$, dentin matrix acidic phosphoprotein-1; COL1, collagen-1; COL3, collagen-3; CD31, cluster of differentiation31; VEGF165, vascular endothelial growth factor-165; VEGF189, vascular endothelial growth factor-189; EDN1, endothelin-1.

dissolution of the three-dimensional biological matrix fibrin will occur. As in fracture healing, cells migrate through the three-dimensional biological matrix and might be directly or indirectly directed through cytokines or growth factors released [41]. We observed migration of ASCs from BCP into the fibrin gel, which likely also occurs after implantation of composites in vivo. Later, fibrous tissue will be formed replacing fibrin, thereby holding cell-seeded BCP in place. Thus, our composites seem promising candidates for bone augmentation in vivo.

BCP-based composites might fit in a one-step surgical procedure. We used an expanded stem cell pool consisting of a homogeneous mixture of cells. However, only a freshly isolated stromal vascular fraction will fit in a one-step surgical procedure [42]. Stromal vascular fraction consists of a 
heterogeneous mixture of cells including endothelial cells and lineage-committed progenitor cells and is not characterized while our stem cell pool was characterized [14, 43]. To determine whether freshly isolated stromal vascular fraction gives similar results in BCP-fibrin composites, it is necessary to test the osteogenic and/or vasculogenic differentiation potential of composites with freshly isolated stromal vascular fraction seeded on BCPs with different HA/ $\beta$-TCP ratios incorporated in fibrin gels.

In summary, BCP20/80-based composites showed increased ALP activity as well as DMP1, CD31, and VEGF189 gene expression compared to BCP60/40-based composites (Figure 6). In addition, BCP20/80-based composites showed increased fibrin degradation. Therefore, we conclude that BCP20/80-based composites showed enhanced osteogenic and vasculogenic differentiation potential compared to BCP60/40-based composites in vitro, suggesting that BCP20/ 80 -based composites might be more promising for in vivo bone augmentation than BCP60/40-based composites.

\section{Competing Interests}

The authors declare that there is no conflict of interests regarding the publication of this paper.

\section{Acknowledgments}

The work of Fransisca A. S. van Esterik was supported by a grant from the University of Amsterdam for the stimulation of a research priority area Oral Regenerative Medicine. The authors thank Henk-Jan Prins, Benno Naaijkens, and Jolanda Hogervorst for adipose stem cell isolation, Ester Weijers and Pieter Koolwijk for providing fibrinogen, thrombin, and advice, Leo van Ruijven for microcomputed tomography evaluation, and Institut Straumann AG for providing Straumann BoneCeramic 20/80.

\section{References}

[1] M. N. Helder, M. Knippenberg, J. Klein-Nulend, and P. I. J. M. Wuisman, "Stem cells from adipose tissue allow challenging new concepts for regenerative medicine," Tissue Engineering, vol. 13, no. 8, pp. 1799-1808, 2007.

[2] S. A. Zijderveld, I. R. Zerbo, J. P. A. van den Bergh, E. A. J. M. Schulten, and C. M. ten Bruggenkate, "Maxillary sinus floor augmentation using a $\beta$-tricalcium phosphate (Cerasorb) alone compared to autogenous bone grafts," The International Journal of Oral \& Maxillofacial Implants, vol. 20, no. 3, pp. 432-440, 2005.

[3] R. F. Ellinger, E. B. Nery, and K. L. Lynch, "Histological assessment of periodontal osseous defects following implantation of hydroxyapatite and biphasic calcium phosphate ceramics: a case report," The International Journal of Periodontics and Restorative Dentistry, vol. 6, no. 3, pp. 22-33, 1986.

[4] J. W. F. H. Frenken, W. F. Bouwman, N. Bravenboer, S. A. Zijderveld, E. A. J. M. Schulten, and C. M. ten Bruggenkate, "The use of Straumann ${ }^{\circledR}$ Bone Ceramic in a maxillary sinus floor elevation procedure: a clinical, radiological, histological and histomorphometric evaluation with a 6-month healing period," Clinical Oral Implants Research, vol. 21, no. 2, pp. 201-208, 2010.
[5] R. Z. LeGeros, "Variability of HAP/ $\beta$-TCP ratios in sintered apatites," Journal of Dental Research, vol. 65, no. 110, p. 292, 1986.

[6] G. Daculsi, R. Z. LeGeros, E. Nery, K. Lynch, and B. Kerebel, "Transformation of biphasic calcium phosphate ceramics in vivo: ultrastructural and physicochemical characterization," Journal of Biomedical Materials Research, vol. 23, no. 8, pp. 883894, 1989.

[7] R. Fujita, A. Yokoyama, T. Kawasaki, and T. Kohgo, "Bone augmentation osteogenesis using hydroxyapatite and $\beta$-tricalcium phosphate blocks," Journal of Oral and Maxillofacial Surgery, vol. 61, no. 9, pp. 1045-1053, 2003.

[8] C. M. Schmitt, H. Doering, T. Schmidt, R. Lutz, F. W. Neukam, and K. A. Schlegel, "Histological results after maxillary sinus augmentation with Straumann ${ }^{\circledR}$ BoneCeramic, Bio$\mathrm{Oss}^{\circledR}, \mathrm{Puros}^{\circledR}$, and autologous bone. A randomized controlled clinical trial," Clinical Oral Implants Research, vol. 24, no. 5, pp. 576-585, 2013.

[9] C. Lindgren, A. Mordenfeld, and M. Hallman, "A prospective 1-year clinical and radiographic study of implants placed after maxillary sinus floor augmentation with synthetic biphasic calcium phosphate or deproteinized bovine bone," Clinical Implant Dentistry and Related Research, vol. 14, no. 1, pp. 41-50, 2012.

[10] A. K. Guha, S. Singh, R. Kumaresan, S. Nayar, and A. Sinha, "Mesenchymal cell response to nanosized biphasic calcium phosphate composites," Colloids and Surfaces B: Biointerfaces, vol. 73, no. 1, pp. 146-151, 2009.

[11] A. Vats, R. C. Bielby, N. S. Tolley, R. Nerem, and J. M. Polak, "Stem cells," The Lancet, vol. 366, no. 9485, pp. 592-602, 2005.

[12] M. J. Oedayrajsingh Varma, R. G. M. Breuls, T. E. Schouten et al., "Phenotypical and functional characterization of freshly isolated adipose tissue-derived stem cells," Stem Cells and Development, vol. 16, no. 1, pp. 91-104, 2007.

[13] C. M. Cowan, Y.-Y. Shi, O. O. Aalami et al., "Adipose-derived adult stromal cells heal critical-size mouse calvarial defects," Nature Biotechnology, vol. 22, no. 5, pp. 560-567, 2004.

[14] P. A. Zuk, M. Zhu, P. Ashiian et al., "Human adipose tissue is a source of multipotent stem cells," Molecular Biology of the Cell, vol. 13, no. 12, pp. 4279-4295, 2002.

[15] V. Planat-Benard, J.-S. Silvestre, B. Cousin et al., "Plasticity of human adipose lineage cells toward endothelial cells: physiological and therapeutic perspectives," Circulation, vol. 109, no. 5, pp. 656-663, 2004.

[16] H. J. Prins, M. N. Helder, J. R. Overman, C. M. ten Bruggenkate, E. A. J. M. Schulten, and J. Klein-Nulend, "Bone augmentation with adipose stem cells and calcium phosphate carriers for human maxillary sinus floor elevation: an ongoing phase I clinical trial," in Proceedings of the 9th Annual Symposium on Adipose Stem Cells and Clinical Applications of Adipose Tissue, p. 54, Miami, Fla, USA, 2011.

[17] D. L. Hutton, E. M. Moore, J. M. Gimble, and W. L. Grayson, "Platelet-derived growth factor and spatiotemporal cues induce development of vascularized bone tissue by adipose-derived stem cells," Tissue Engineering Part A, vol. 19, no. 17-18, pp. 20762086, 2013.

[18] C. Correia, W. Grayson, R. Eton et al., "Human adipose-derived cells can serve as a single-cell source for the in vitro cultivation of vascularized bone grafts," Journal of Tissue Engineering and Regenerative Medicine, vol. 8, no. 8, pp. 629-639, 2014. 
[19] M. C. Moore, V. Pandolfi, and P. S. McFetridge, "Novel humanderived extracellular matrix induces in vitro and in vivo vascularization and inhibits fibrosis," Biomaterials, vol. 49, pp. 37-46, 2015.

[20] L. Le Guehennec, E. Goyenvalle, E. Aguado et al., "MBCP ${ }^{\circledR}$ biphasic calcium phosphate granules and tissucol ${ }^{\circledR}$ fibrin sealant in rabbit femoral defects: the effect of fibrin on bone ingrowth," Journal of Materials Science: Materials in Medicine, vol. 16, no. 1, pp. 29-35, 2005.

[21] D. Le Nihouannen, A. Saffarzadeh, O. Gauthier et al., "Bone tissue formation in sheep muscles induced by a biphasic calcium phosphate ceramic and fibrin glue composite," Journal of Materials Science: Materials in Medicine, vol. 19, no. 2, pp. 667-675, 2008.

[22] M. Bagot D’Arc and G. Daculsi, "Micro macroporous biphasic ceramics and fibrin sealant as a moldable material for bone reconstruction in chronic otitis media surgery. A 15 years experience," Journal of Materials Science: Materials in Medicine, vol. 14, no. 3, pp. 229-233, 2003.

[23] M. Bagot d'Arc, G. Daculsi, and N. Emam, "Biphasic ceramics and fibrin sealant for bone reconstruction in ear surgery," Annals of Otology, Rhinology and Laryngology, vol. 113, no. 9, pp. 711-720, 2004.

[24] Y. Yamada, J. S. Boo, R. Ozawa et al., "Bone regeneration following injection of mesenchymal stem cells and fibrin glue with a biodegradable scaffold," Journal of Cranio-Maxillofacial Surgery, vol. 31, no. 1, pp. 27-33, 2003.

[25] W. Bensaïd, J. T. Triffitt, C. Blanchat, K. Oudina, L. Sedel, and H. Petite, "A biodegradable fibrin scaffold for mesenchymal stem cell transplantation," Biomaterials, vol. 24, no. 14, pp. 2497-2502, 2003.

[26] S. S. Jensen, M. M. Bornstein, M. Dard, D. D. Bosshardt, and D. Buser, "Comparative study of biphasic calcium phosphates with different HA/TCP ratios in mandibular bone defects. A long-term histomorphometric study in minipigs," Journal of Biomedical Materials Research Part B: Applied Biomaterials, vol. 90, no. 1, pp. 171-181, 2009.

[27] Y. Kuboki, Q. Jin, and H. Takita, "Geometry of carriers controlling phenotypic expression in BMP-induced osteogenesis and chondrogenesis," The Journal of Bone \& Joint SurgeryAmerican Volume, vol. 83, supplement 1, part 2, pp. S105-S115, 2001.

[28] T. L. Arinzeh, T. Tran, J. Mcalary, and G. Daculsi, "A comparative study of biphasic calcium phosphate ceramics for human mesenchymal stem-cell-induced bone formation," Biomaterials, vol. 26, no. 17, pp. 3631-3638, 2005.

[29] O. H. Lowry, "Micromethods for the assay of enzyme II specific procedure. Alkaline phosphatase," Methods in Enzymology, vol. 4, p. 371, 1995.

[30] E. M. Weijers, M. H. van Wijhe, L. Joosten et al., "Molecular weight fibrinogen variants alter gene expression and functional characteristics of human endothelial cells," Journal of Thrombosis and Haemostasis, vol. 8, no. 12, pp. 2800-2809, 2010.

[31] J. R. Overman, E. Farré-Guasch, M. N. Helder, C. M. ten Bruggenkate, E. A. J. M. Schulten, and J. Klein-Nulend, "Short (15 minutes) bone morphogenetic protein-2 treatment stimulates osteogenic differentiation of human adipose stem cells seeded on calcium phosphate scaffolds in vitro," Tissue Engineering Part A, vol. 19, no. 3-4, pp. 571-581, 2013.

[32] E. M. Weijers, L. J. van den Broek, T. Waaijman, V. W. M. van Hinsbergh, S. Gibbs, and P. Koolwijk, "The influence of hypoxia and fibrinogen variants on the expansion and differentiation of adipose tissue-derived mesenchymal stem cells," Tissue Engineering Part A, vol. 17, no. 21-22, pp. 2675-2685, 2011.

[33] L. Saldaña, S. Sánchez-Salcedo, I. Izquierdo-Barba et al., "Calcium phosphate-based particles influence osteogenic maturation of human mesenchymal stem cells," Acta Biomaterialia, vol. 5, no. 4, pp. 1294-1305, 2009.

[34] A. M. C. Barradas, H. A. M. Fernandes, N. Groen et al., "A calcium-induced signaling cascade leading to osteogenic differentiation of human bone marrow-derived mesenchymal stromal cells," Biomaterials, vol. 33, no. 11, pp. 3205-3215, 2012.

[35] I. R. Zerbo, A. L. J. J. Bronckers, G. de Lange, and E. H. Burger, "Localisation of osteogenic and osteoclastic cells in porous $\beta$ tricalcium phosphate particles used for human maxillary sinus floor elevation," Biomaterials, vol. 26, no. 12, pp. 1445-1451, 2005.

[36] R. Z. LeGeros, "Biodegradation and bioresorption of calcium phosphate ceramics," Clinical Materials, vol. 14, no. 1, pp. 65-88, 1993.

[37] S. Khetan, M. Guvendiren, W. R. Legant, D. M. Cohen, C. S. Chen, and J. A. Burdick, "Degradation-mediated cellular traction directs stem cell fate in covalently crosslinked three-dimensional hydrogels," Nature Materials, vol. 12, no. 5, pp. 458-465, 2013.

[38] D. Shweiki, A. Itin, D. Soffer, and E. Keshet, "Vascular endothelial growth factor induced by hypoxia may mediate hypoxiainitiated angiogenesis," Nature, vol. 359, no. 6398, pp. 843-845, 1992.

[39] H. Masukawa, Y. Miura, I. Sato, Y. Oiso, and A. Suzuki, "Stimulatory effect of endothelin-1 on Na-dependent phosphate transport and its signaling mechanism in osteoblast-like cells," Journal of Cellular Biochemistry, vol. 83, no. 1, pp. 47-55, 2001.

[40] A. J. Engler, S. Sen, H. L. Sweeney, and D. E. Discher, "Matrix elasticity directs stem cell lineage specification," Cell, vol. 126, no. 4, pp. 677-689, 2006.

[41] B. A. Bromberek, P. A. J. Enever, D. I. Shreiber, M. D. Caldwell, and R. T. Tranquillo, "Macrophages influence a competition of contact guidance and chemotaxis for fibroblast alignment in a fibrin gel coculture assay," Experimental Cell Research, vol. 275, no. 2, pp. 230-242, 2002.

[42] E. Farré-Guasch, H.-J. Prins, J. R. Overman et al., "Human maxillary sinus floor elevation as a model for bone regeneration enabling the application of one-step surgical procedures," Tissue Engineering Part B: Reviews, vol. 19, no. 1, pp. 69-82, 2013.

[43] P. A. Zuk, M. Zhu, H. Mizuno et al., "Multilineage cells from human adipose tissue: implications for cell-based therapies," Tissue Engineering, vol. 7, no. 2, pp. 211-228, 2001. 

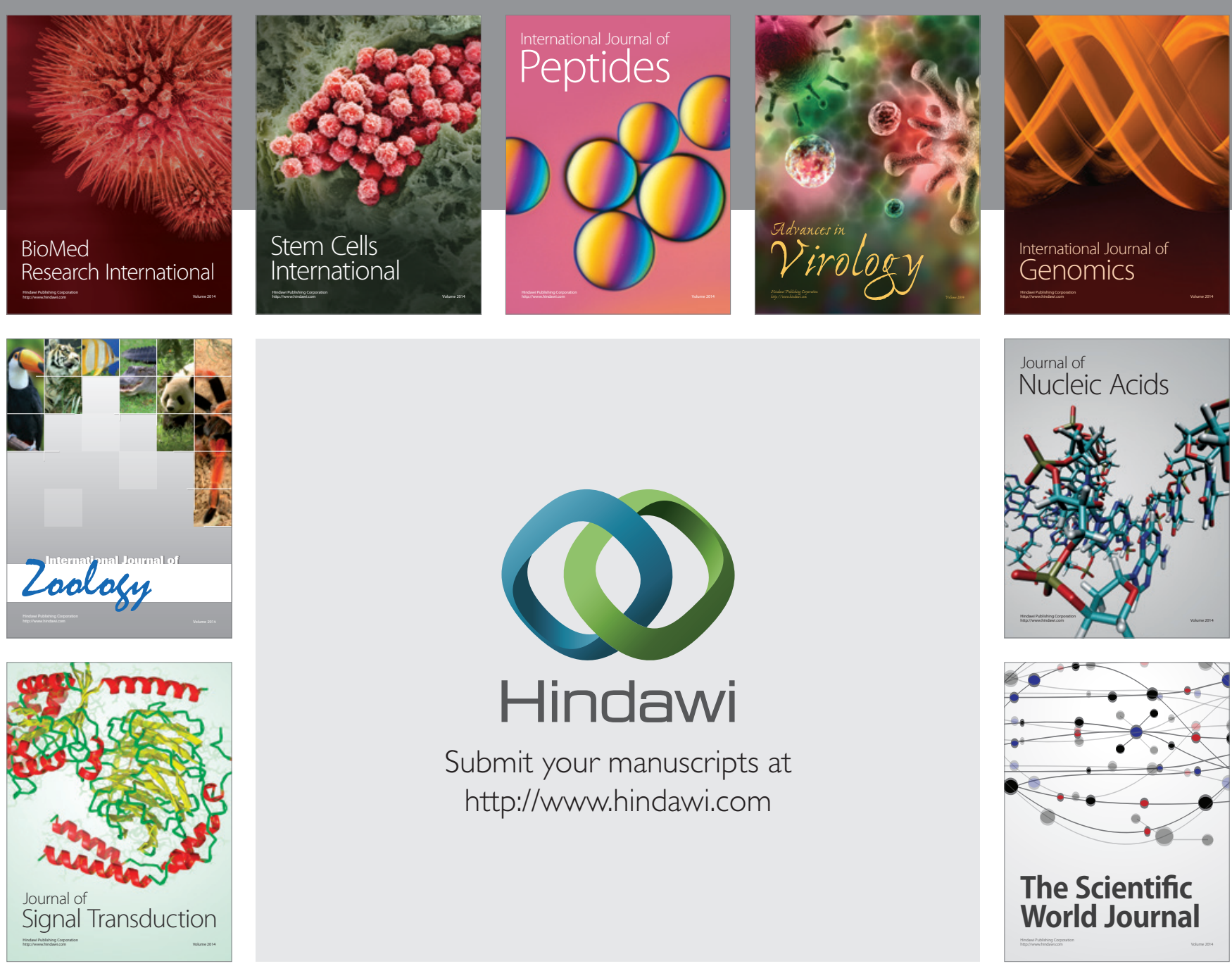

Submit your manuscripts at

http://www.hindawi.com
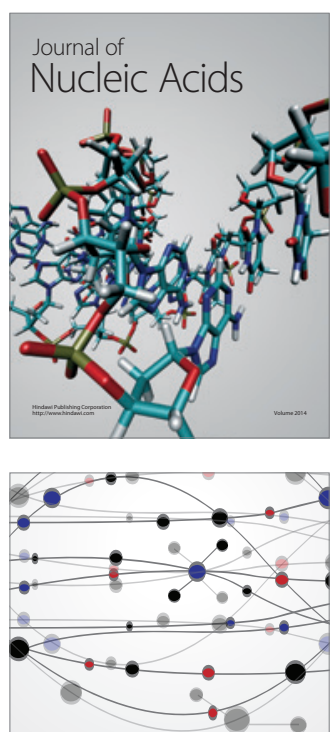

The Scientific World Journal
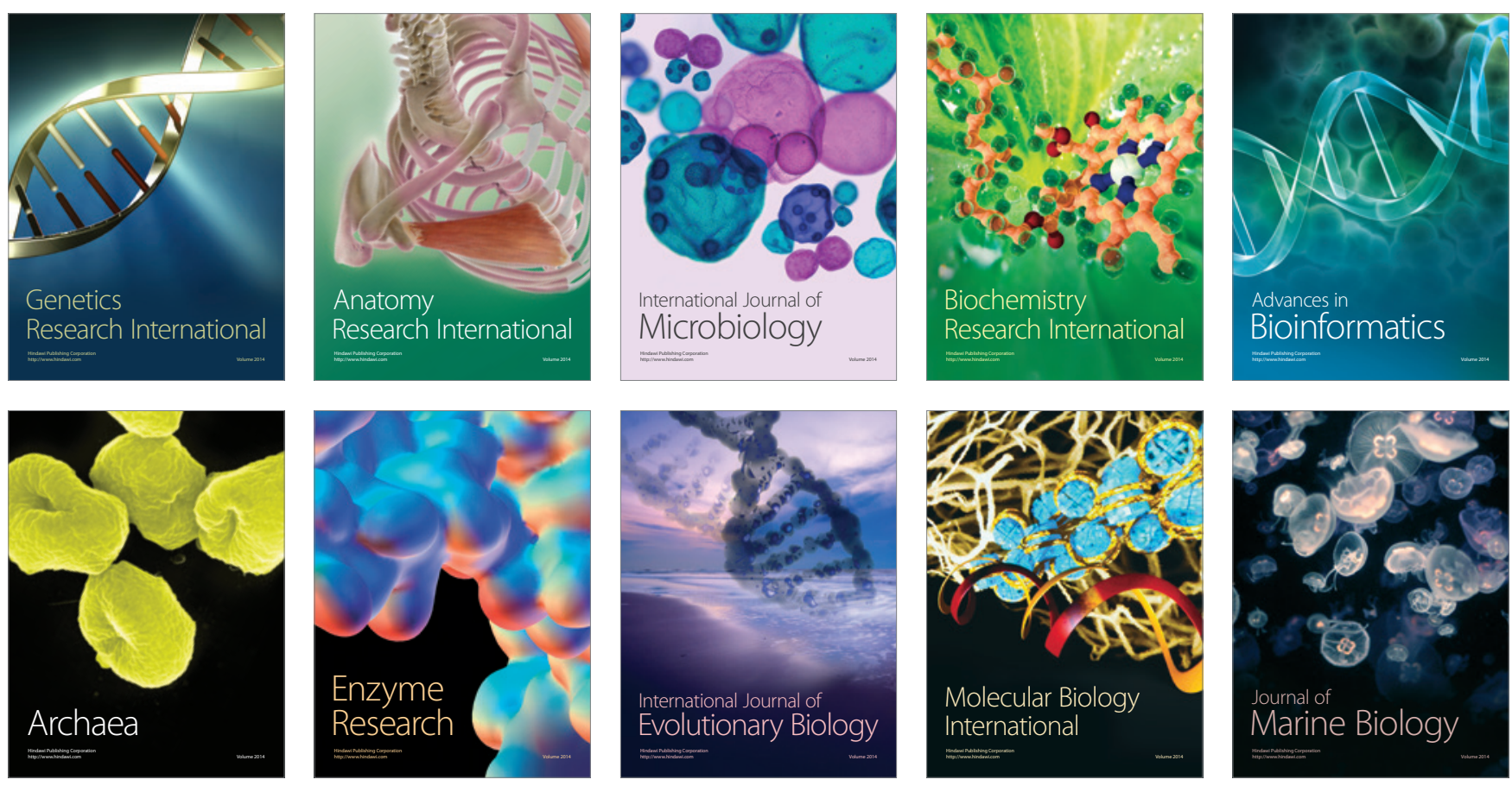